\title{
Twins in Nature, Science, and Society
}

\author{
L. GEDDA \\ The Gregor Mendel Institute of Medical Genetics and Twin Research, Rome, Italy
}

Rome is certainly one of the places in the world which speaks to us of twins more than any other, and, in Rome itself, the Capitoline Hall of the Horatii and Curiatii triplets. From the myth of Romulus and Remus, history gradually passes through the tale of the triplets from Rome and Albalonga, who prevented a bigger war, up to the memory of the Emperor-philosopher Marcus Aurelius, who had twin sons.

Today, however, not only legend and history deal with twins, but also science and particularly demography and genetics do so as well.

Demography discovers constants in the frequency of the phenomenon of twins, and this presents characteristic variabilities which aid in reconstructing the ethnological events of the human species. The example of Italy is characteristic (see sketch on the cover of the book).

Genetics has found in twins a special motif of interest, in that about one-third of the twins are identical, that is, they have the same hereditary patrimony. On the basis of this phenomenon, twins hereditarily different are also utilized, and special study methods have been set up. The study of twins today opens up in a special way a new field of Genetics, of which they represent the most important and demonstrative test: the heredity of biological time, or Chronogenetics.

All hereditary or acquired diseases, therefore, find in the comparison of $\mathrm{MZ}$ and $\mathrm{DZ}$ twins many possibilities for the specific study of epidemiology, pathogenesis, symptomatology, and treatment.

The psychology of twins also is of particular interest, both as a test of heredity and of acquired characteristics because of there being two of them (couple effect).

The interest and needs found in the twin population demand the assistance in a special way of public authorities regarding what has to be done.

Prof. Luigi Gedda, Istituto Mendel, Piazza Galeno 5, oor6i Roma, Italy 